\title{
Examination of Pons-Cerebellum Cisterna Anatomy by Endoscopic Retrosigmoid Suboccxipital Approach: Cadaveric Study
}

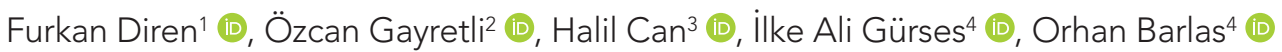 \\ 'Department of Brain and Nerve Surgery, Gaziosmanpaşa Taksim Training and Research Hospital, i̇stanbul, Turkey \\ ${ }^{2}$ Department of Anatomy, İstanbul University İstanbul School of Medicine, İstanbul, Turkey \\ ${ }^{3}$ Department of Brain and Nerve Surgery, Biruni University School of Medicine, İstanbul, Turkey \\ ${ }^{4}$ Department of Brain and Nerve Surgery, İstanbul University İstanbul School of Medicine, İstanbul, Turkey
}

Cite this article as: Diren F, Gayretli Ö, Can H, Gürses IA, Barlas O. Examination of Pons-Cerebellum Cisterna Anatomy by Endoscopic Retrosigmoid Suboccxipital Approach: Cadaveric Study. JAREM 2019; 9(3): 140-7.

\begin{abstract}
Objective: Endoscopic interventions are rapidly replacing conventional methods in neurosurgical applications. The main purpose of this study was to examine the neurovascular structures in the pons-cerebellum cistern in detail through the endoscopic retrosigmoid suboccipital approach and to make morphometric measurements.

Methods: In five human dry cadavers, pons-cerebellum cisterna was examined by endoscopic retrosigmoid approach. Relations with the vascular structures surrounding the nerves, the dimensions of the craniectomy diameter, the distances of the petrosal vein and the trigeminal and facial-vestibulocochlear nerves to the dura, the length of the nerves, the diameter of the trigeminal nerves, and the distance between the nerves and petrosal vein were measured.

Results: The distances between the dura and the petrosal vein, trigeminal nerve and facial-vestibulocochlear nerves were 34-53 mm (mean, 43.5 $\mathrm{mm}$ ), 46-62 mm (mean, $54.1 \mathrm{~mm}$ ), and 37-47 mm (mean, $42 \mathrm{~mm}$ ), respectively. The diameter of the trigeminal nerve was measured as 1.27-3.27 $\mathrm{mm}$ (mean, $1.8 \mathrm{~mm}$ ). The distances between the petrosal vein and the trigeminal nerve and facial-vestibulocochlear nerves were 6-13 $\mathrm{mm}$ (mean, $9.5 \mathrm{~mm}$ ) and 6-12 $\mathrm{mm}$ (mean, $8.6 \mathrm{~mm}$ ), respectively, and the distance between the trigeminal nerve and facial-vestibulocochlear nerves was $9-15 \mathrm{~mm}$ (mean, $10.1 \mathrm{~mm}$ ). Arterial compression was observed at the five trigeminal nerves and five fascial-vestibulocochlear nerves.

Conclusion: In this study, pons-cerebellum cistern and anatomical neurovascular structures in this place were able to examine with endoscope in detail. Vascular compression was frequently observed in trigeminal nerve and facial-vestibulocochlear nerves.
\end{abstract}

Keywords: Dry cadaver, neuroendoscopy, trigeminal neuralgia, pontocerebellar cistern

\section{INTRODUCTION}

In 1910, L'Espinasse reported the first use of endoscopes in neurosurgery by the cauterization of choroid plexuses using a cystoscope in two children with hydrocephalus $(1,2)$. In 1917, Eugène-Louis Doyen defined retrogasserian neurotomy with the first endoscopic approach to trigeminal nerve sensory root with retrosigmoid suboccipital craniectomy and developed surgical instruments for this surgical procedure (2). In subsequent years, parallel to technological advances, endoscopy has been used frequently in cranial and spinal neurosurgical surgeries. Paolo Cappabianca and Enrico de Divitiis described the ex- tended endoscopic transnasal transsphenoidal approach to interfere to the sellar and parasellar lesions and designed surgical hand tools suitable for this surgery $(3,4)$. In 2002, Shahinian et al. (5) published the first full endoscopic vascular decompression surgery of the trigeminal nerve. These approaches have become much more popular in the last 10 years. In the present study, details of the anatomy of the cerebellopontine cistern and the neural and vascular structures in it and the endoscopic access pathway to this area, the dimensions of these structures and their distance to each other, and the visibility of the anatomical structures within the cisterns beyond the cerebellopontine cistern are evaluated. 


\section{METHODS}

The present study was performed on five adult dry cadavers in the Istanbul University, Istanbul School of Medicine, Department of Anatomy. Telescopes, endoscopy sets, and microsurgical hand tools were used in the study. The Karl-Storz Hopkins II rigid endoscopes with $0^{\circ}$ angle, $2 \mathrm{~mm}$ diameter, and $26 \mathrm{~mm}$ length and $30^{\circ}$ angle, 2.9 $\mathrm{mm}$ diameter, and $30 \mathrm{~cm}$ length were used in the study. After the endoscope was inserted into the study cannula, dissections were performed using endoscopic micro hand tools from the study cannula. Measurements were made using the endoscope shafts of the endoscope and the millimetric scale hooks (MSH) that we designed.

The cadavers were placed on the anatomy dissection table in the prone position, with the heads lying outside the table. The face was positioned by rotating approximately $30^{\circ}$ to the opposite side of the field to be studied. Retrosigmoid suboccipital craniectomy was performed, and craniectomy diameters were measured. The relationship between the asterion and the transverse-sigmoid sinus junction was investigated. The endoscope was pushed forward with minimal cerebellar retraction through the opening close to the transverse-sigmoid sinus junction. The closest distance between the point where the petrosal vein was connected to the petrosal vein complex and the dura was measured using the endoscope shaft. The lateral wall of the cerebellopontine cistern extending from inside to outside through the internal acoustic meatus and the Meckel's cave, the posterior wall of the anterior cerebellar hemisphere formed by the posterior quadrangular and superior semilunar lobule, the medial wall formed by pons and anterior pontine membrane, the lateral pontomesencephalic membrane separating from the ambient cistern below the tentorial opening and forming the superior wall, and the lateral pontomedullary membrane forming the arachnoid wall in the inferior and allowing the separation from the cerebellomedullary cistern were visualized by proceeding through the posterior petrous part of the temporal bone. The distances of the trigeminal and facial-vestibulocochlear nerves to the dura were measured by using the endoscope shaft. In the cistern, the length of the trigeminal nerves from the Meckel's cave to the root entrance region and the lengths of the facial and vestibulocochlear nerves from the internal acoustic meatus to the root entry points were measured by using MSH. The closest distances of the facial and vestibulocochlear nerves from the exit points in the internal acoustic meatus to the exit points of the trigeminal nerves in the Meckel's cave and to the entrance points of the petrosal veins into the dura were measured by using MSH. The closest distances of the trigeminal nerves from the exit points in the Meckel's cave to the entrance points of the petrosal veins into the dura were measured by using MSH. The relationship between the trigeminal and facial-vestibulocochlear nerves with the vessels around them was investigated. The part of the abducens nerve within the cistern, its entrance to the Dorello canal, and its relationship with the anterior inferior cerebellar artery were examined. The anterior pontine membrane was cut to examine the prepontine cistern, the lateral pontomesencephalic membrane was cut to examine the ambient cistern, and the lateral pontomedullary membrane was cut to examine the cerebellomedullary cistern. Ethics committee approval was received for this study from the Ethics Committee of İstanbul University, İstanbul School of Medicine.

\section{RESULTS}

The mean craniectomy diameter was 19.1 (17-25) mm. The diameter of the craniectomy should be at least $17 \mathrm{~mm}$ for the study.

When the relationship between the location and distance of the transverse-sigmoid joint and asterion was evaluated, the asterion and transverse-sigmoid joint were found to be adjacent to each other in $70 \%$ and were in different localizations in $30 \%$ of the cases. Therefore, the diameter of the craniectomy and the length of the incision varied.

The arachnoid membranes covering the cerebellopontine cistern were observed to show continuity from top to bottom. In the anterolateral aspect of the cerebellopontine cistern, it was observed that the petrosal vein progressed in the arachnoid membranes, penetrated through the arachnoid membranes, and attached to the superior petrosal sinus. The petrosal vein was observed to be in the superolateral aspect of the trigeminal nerve in all cadavers (Figure 1). When the cistern was entered, the distances of the petrosal vein, trigeminal nerve, and facial-vestibulocochlear nerves to the dura and to each other and the lengths of the trigeminal nerve and facial-vestibulocochlear nerves within the cistern were measured. The measurements are listed in Table 1.

Most of the membranes forming the walls of the cerebellopontine cistern and the anatomical structures in the adjacent cisterns are easily visualized due to the generally atrophic nature of dry cadaveric tissues.

The trochlear nerves in the ambient cistern were seen behind the lateral pontomesencephalic membrane that has a transparent tulle view (Figure 2).

The lower cranial nerves within the lateral cerebellomedullary cistern were visualized behind the lateral pontomedullary membrane.

In the interpeduncular cistern, the proximal parts of the superior cerebellar and posterior cerebral arteries and the oculomotor nerves in their own arachnoid sheath were visualized (Figure 3)

When the trigeminal nerves were examined in one cadaver, a large trigeminal cistern was observed around the nerve, leaving a space around the trigeminal nerve; in other cadavers, cisternal formation in the form of thin arachnoid membranes and bands that winded the trigeminal nerve tightly was seen (Figure 4).

When portio major and portio minor fibers of 10 trigeminal nerves were examined, in 5 of 10, it was possible to differentiate the portio major and the portio minor fibers, whereas in the other 5 , no distinction could be made (Figure 5).

It was observed that a vessel was passed through the left abducens nerve in one cadaver (Figure 6), whereas the nerves were in place in other cadavers.

When the superior cerebellar arteries in the cerebellopontine cistern were examined, it was seen that one of the superior cerebellar arteries appeared as a pair from the basilar artery, three of them were separated into two branches in the medial of the trigeminal nerve after leaving the basilar artery, and the others were divided into two branches at the superior of the trigeminal nerve. It was observed that the superior cerebellar arteries were 


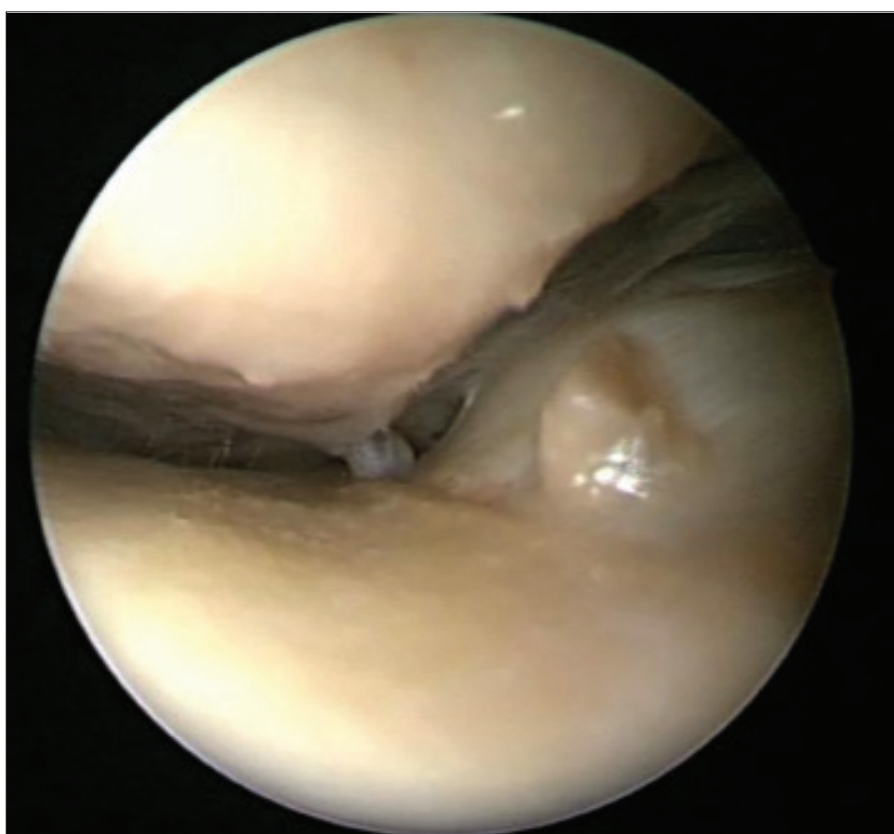

Figure 1. View of the petrosal vein at the entrance to the cerebellopontine cistern via a $0^{\circ}$ telescope

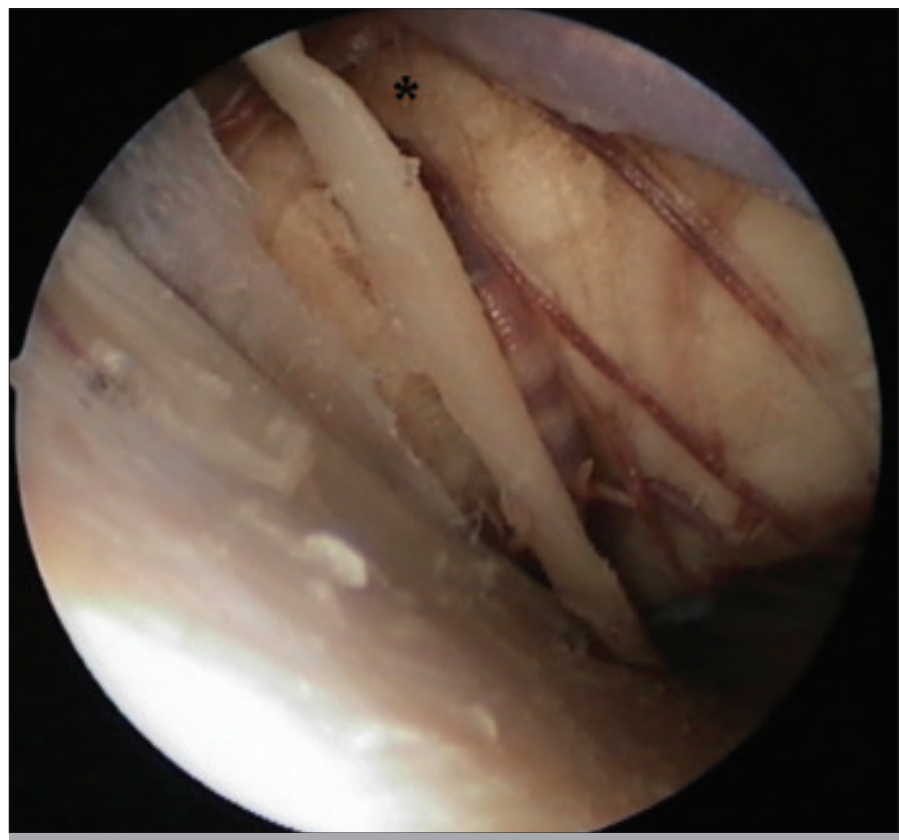

Figure 2. Image of the * nervus trochlearis in the left ambient cistern via a $0^{\circ}$ endoscope

most commonly found in the superior of the trigeminal nerves.

In all of the cerebellopontine cisterns examined, it was seen that the anterior inferior cerebellar arteries originated from their sites singly. The labyrinthine artery was observed to be originating from the basilar artery in one cadaver, whereas it was from the anterior inferior cerebellar artery in other cadavers. The anterior inferior cerebellar arteries were most commonly located in the inferior of the facial-vestibulocochlear nerves.

In 5 of 10 trigeminal nerves examined, six vascular compressions were observed. The nerve was compressed by the anterior infe-

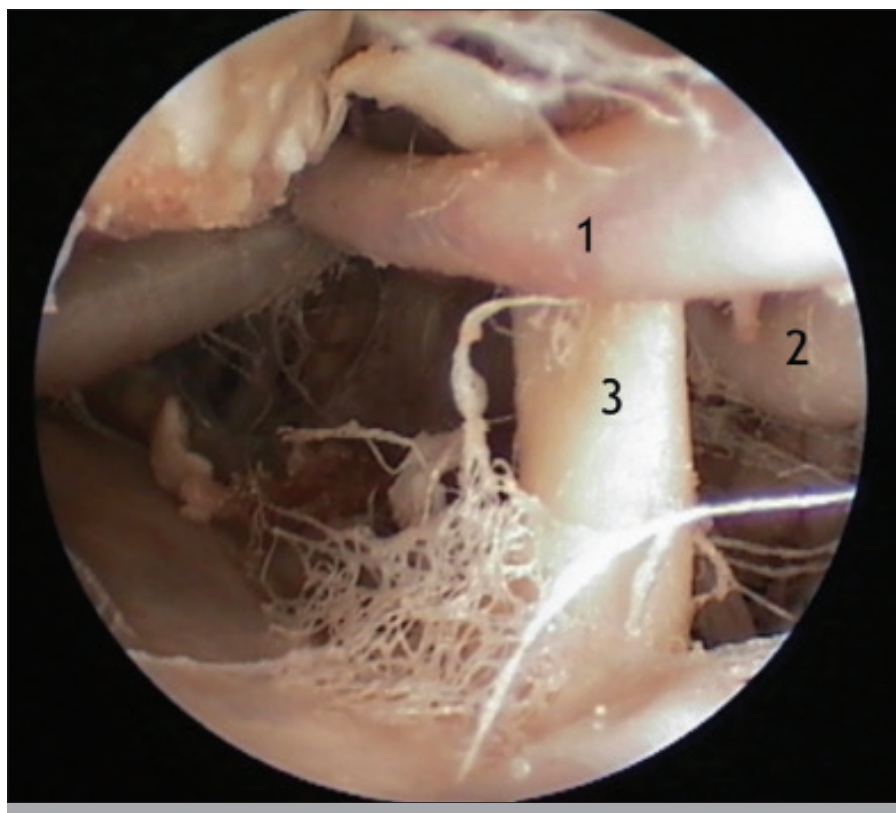

Figure 3. Image of the anatomical structures in the interpeduncular cistern (1: superior cerebellar artery; 2: posterior cerebral artery; 3: oculomotor nerve)

rior cerebellar artery in two, by the superior cerebellar artery in three (Figure 7), and by both the anterior inferior cerebellar artery and superior cerebellar artery in one of the cases. Two of the trigeminal nerves that had vascular compression were on the right, and three of them were on the left side.

While vascular compression was observed in five of the facial and the vestibulocochlear nerves examined, the anterior inferior cerebellar artery was found to be the vessels causing the compression.

\section{DISCUSSION}

When the study on dry cadavers was evaluated with respect to endoscopy training and surgical applications, it was seen that dry cadavers had some advantages in addition to their disadvantages with respect to education. Cerebrospinal fluid flow and intervention of blood to the cerebellopontine cistern that impairs the visual clarity of endoscopic images were not observed in dry cadaver brains on the contrary to the live. In addition, atrophic dry cadaveric tissues were found to provide a larger study area than fresh cadavers and living ones. All these factors were found to be important advantages in the endoscopic surgery training stage. Cerebellar tissues of formalin-fixed dry cadavers were found to be fragile and easily damaged during cerebellar retraction and shed into the cerebellopontine cistern. In this case, the pollution of the studied area was seen as a significant disadvantage. O'Donoghue and Cappabianca proposed cadaveric studies $(6,7)$ before the endoscopic surgical intervention in humans, whereas Jarrahy proposed to study on live animal (pig) model (8). In the present study, our experience has suggested that to learn the principles of endoscopic surgery and the anatomy of the area to be studied in dry cadavers first and then to develop surgical skills in animal models would be useful.

In surgical interventions directed to the cerebellopontine cistern, the supine or lateral lying positions are generally used to prevent the cerebellum from entering the study area $(9,10)$. The cadavers 

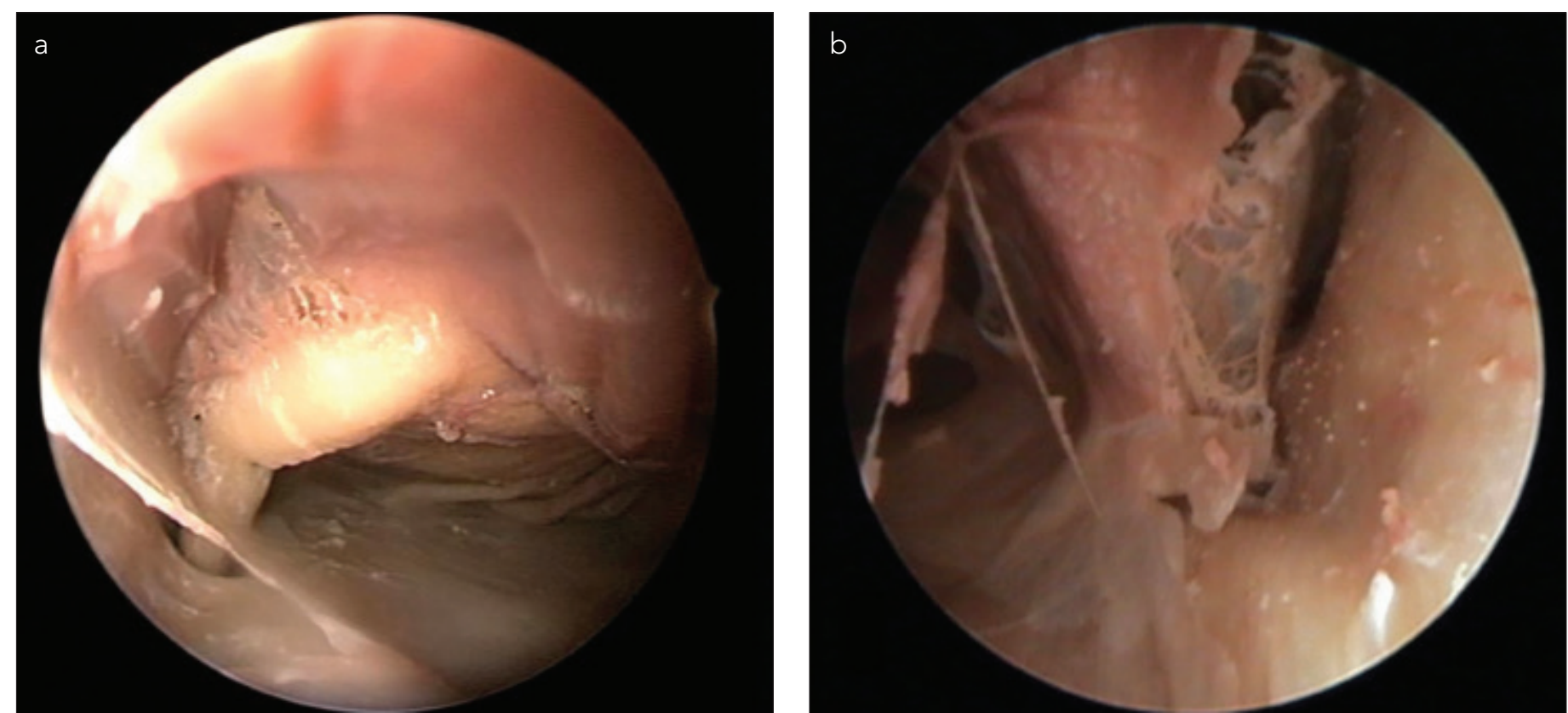

Figure 4. a, b. (a) Image of the trigeminal cistern tightly surrounding the left trigeminal nerve via a $0^{\circ}$ telescope. (b) Image of the right, wide trigeminal cistern via a $0^{\circ}$ telescope
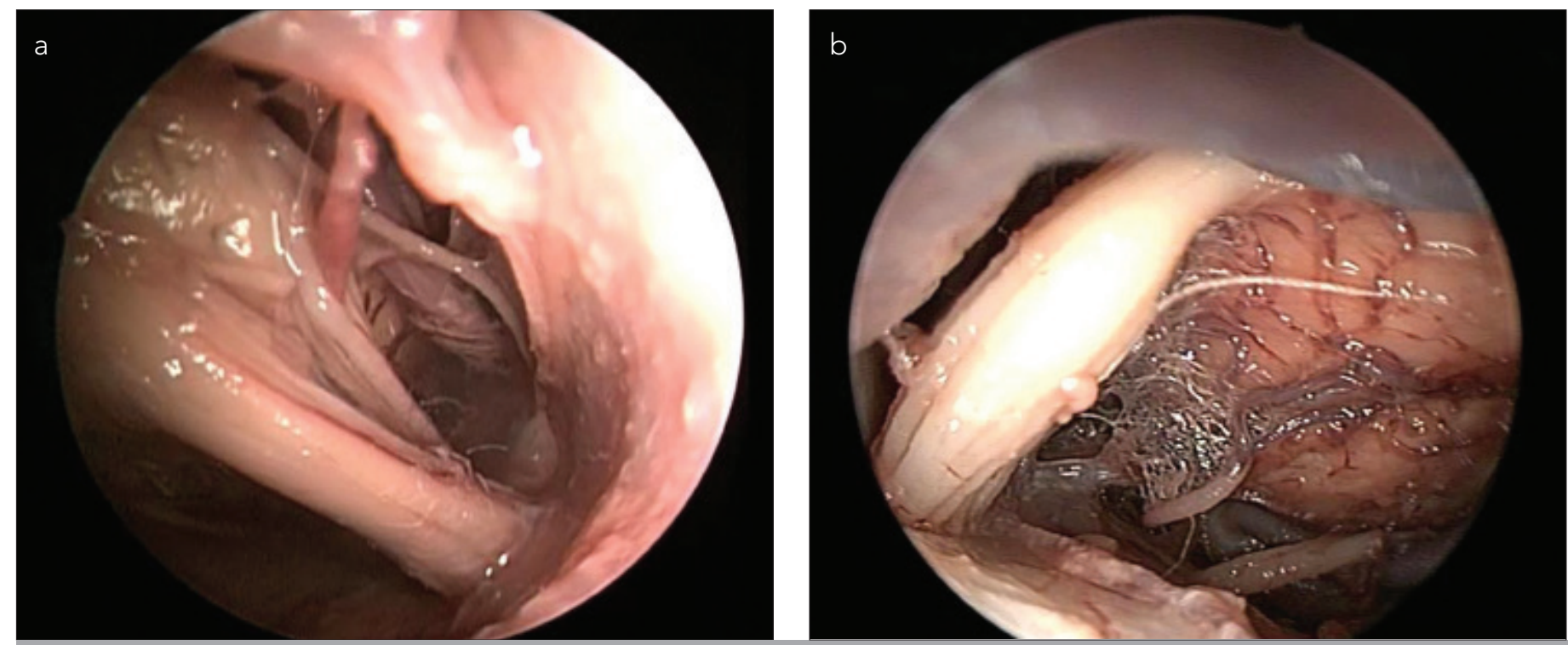

Figure 5. a, b. (a) Image of the motor and sensory roots of the trigeminal nerve that were differentiated from the right side via a $0^{\circ}$ telescope. (b) Image of the motor and sensory roots of the trigeminal nerve that could not be differentiated from the left side via a $30^{\circ}$ telescope

were in the prone position in our study. Since the elasticity of dry cadaver brains was highly decreased and the blood flow in the tissue was not present, the cerebellum did not prolapse into the study area and did not obstruct the endoscopic entry into the cerebellopontine cistern and the study being made. In addition, cadavers were easily placed on the table as no additional tools were needed to fasten the cadavers on the table at the prone position. Owing to these, performing the endoscopic cerebellopontine cistern examination in dry cadavers in the prone position was seen to ease the study technically.

Dry cadaveric studies on the cerebellopontine cistern by the endoscopic retrosigmoid suboccipital approach revealed that the diameter of the craniectomy should be at least $17 \mathrm{~mm}$ in dry. It was seen that when the cerebellopontine cistern was entered through a craniectomy $<17 \mathrm{~mm}$ after the insertion of the endoscope into the study cannula, the mobility of the endoscope was restricted, and the micro instruments could not be angled adequately in the dissection stage. In the endoscopic retrosigmoid approach, a $19 \mathrm{~mm}$ craniectomy was observed to provide adequate space for the use of endoscope and hand tools. Similar results have been also obtained in the studies of the authors in the literature $(11,12)$.

In our study, the investigation of the cerebellopontine cistern with the endoscopic approach was found to be more advanta- 


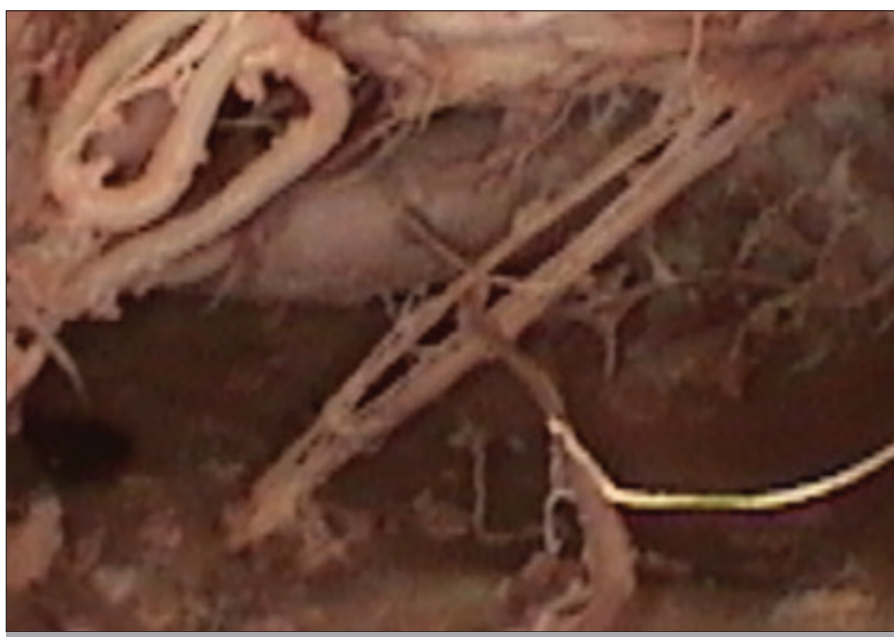

Figure 6. Image of the labyrinthine artery passing through the left abducens nerve via a $0^{\circ}$ telescope

geous than that with the microscopic approaches because of the smaller craniectomy, minimal cerebellar retraction, minimal tension in the cranial nerves due to it, and complete visualization of the inside of the anatomical structures in the cerebellopontine cistern, such as Meckel's cave and internal acoustic meatus. In the literature, the amount of soft tissue and cranial nerve damage is reported to be less due to the small size of the craniectomy, minimal cerebellar retraction, and minimal traction of the cranial nerves. As a result of these, less postoperative pain and faster recovery have been shown to occur (13-18). Thus, the duration of hospital stay is shortened $(14,15)$.

The endoscopic approach has some disadvantages in addition to its advantages when compared with the microscopic approach. The two-dimensional image transferred from the endoscope causes the perception of depth to deteriorate. Two hand tools cannot be used at the same time as the endoscope is used with one hand and a hand tool is used with the other hand. The anatomical structures behind the endoscope tip cannot be visualized because the endoscopic image is obtained from the tip of the endoscope. In these circumstances, the movement of the endoscope shaft and the use of hand tools can damage the anatomical structures behind the endoscope tip. The endoscope tip can be misted due to the temperature difference between the inside of the cadaver and the outside. Similar disadvantages related with endoscopic surgery have been mentioned in the studies published in the literature, and the development of endoscopic transport and washing systems with the advances in technology has led to overcome most of these disadvantages considerably $(4,5,8,9,11,12,14-17,19,20)$.

In our study, the location of the asterion was found to be adjacent to the transverse-sigmoid junction at a rate of $70 \%$ of the cases. In the previous studies, the asterion was generally shown to be adjacent to the transverse-sigmoid junction although differences are seen among communities. The localization of the asteroid below the transverse-sigmoid junction was more frequent than its localization above the transverse-sigmoid junction (21-24).

In the present study, 10 of the 10 petrosal veins examined in five different cadavers were seen to be superolateral to the trigemi-

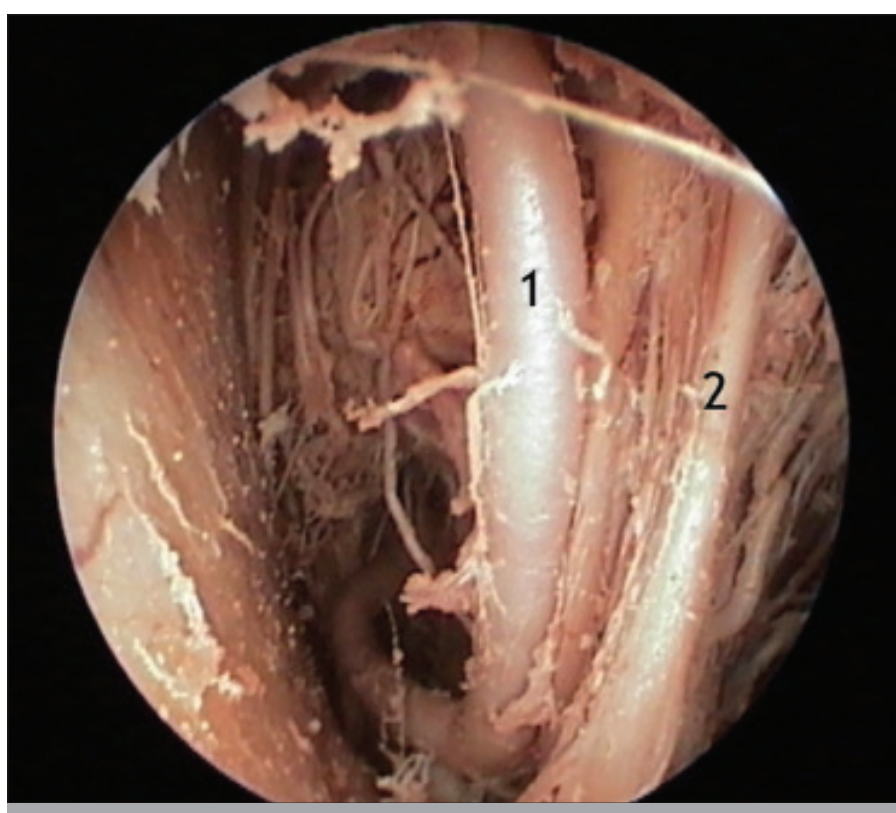

Figure 7. Image of the vascular structure compressing the trigeminal nerve via a $0^{\circ}$ endoscope $(1$, superior cerebellar artery; 2 , trigeminal nerve)

nal nerves. The classification in the study by Tanriöver and Rhoton on the drainage place of the superior petrosal vein complex into the superior petrosal sinus in 15 adult cadavers classified the ones draining into the sinus from the lateral side of the internal acoustic meatus to be 19\% (type I), between the lateral of the point where the trigeminal nerve entered the Meckel's cave and the medial of the point where the facial nerve entered the internal acoustic meatus to be $72 \%$ (type II), and from the medial or superior of the Meckel's cave to be $9 \%$ (type III). The petrosal veins we have seen in our study suited to the type I and type II superior petrosal vein complex groups that show the ones on the lateral aspect of the trigeminal nerve according to the classification by Tanrıöver and Rhoton (25). The findings of our study were in contradiction with the findings by Tanriöver and Rhoton.

The abducens nerve was observed to course in the cerebellopontine cistern anterior to the anterior inferior cerebellar artery, in the medial and inferior of the point where the trigeminal nerve entered the Meckel's cave, and in the lateral of the anterior pontine membrane and then entered the Dorello canal. In the anatomical study by Rhoton on posterior fossa cisterns, the abducens nerve has been observed to course in the lateral aspect of the anterior pontine membrane in the cerebellopontine cistern (26). Yaşargil reported that the abducens nerve is found in the prepontine cistern depending on his observations of subarachnoid cisterns during the cranial surgery he performed (27). While Rhoton's study supports our study, Yaşargil's study shows the opposite.

The portion of the superior cerebellar arteries within the cerebellopontine cistern was seen in the superomedial of the trigeminal nerves in $60 \%$ of the cases. On cerebellopontine cistern examination, it was seen that the artery appeared as a pair in one of the cases, it bifurcated between the basilar arteries and the medial of the trigeminal nerves in three, and it bifurcated in the superior after passing the trigeminal nerve in six. It was seen in contact with the trigeminal nerve at a rate of $20 \%$ with its branches after bifur- 
cation and $20 \%$ with the main branch before bifurcation. Hardy and Rhoton's study showed that the superior cerebellar arteries contact the trigeminal nerves in $52 \%$ of the cases. The branches after bifurcation formed $36 \%$ of these, and the main branches before bifurcation formed $16 \%$. The superior cerebellar artery was observed to arise from the basilar artery as a single branch in 92\% and as a double branch or duplex in $8 \%$ (28).

The portion of the anterior inferior cerebellar arteries within the cerebellopontine cistern was seen to pass in $40 \%$ of the cases through the inferomedial of the facial-vestibulocochlear nerves and in $10 \%$ between the nerves. The anterior inferior cerebellar arteries were observed to course around the three sides of the facial-vestibulocochlear nerves. The anterior inferior cerebellar arteries were seen to arise from the basilar artery as a single branch in all five of the cadavers. In the study by Han on 30 fresh cadavers, the anterior inferior cerebellar arteries were seen to be between the facial and vestibulocochlear nerves in $43.3 \%$ of the cases and around the nerves in 15\% (29). In the study by Yurtsever et al. (20) in which they performed cadaveric dissection and cranial magnetic resonance imaging (MRI) investigation in 74 adults, they observed that the anterior inferior cerebellar arteries are seen between the facial and vestibulocochlear nerves in $32.5 \%$ of the cadaveric dissections and $34.5 \%$ of the cranial MRI investigations of adults (30). Kim showed that the anterior inferior cerebellar arteries are seen to arise from the basilar artery in $98.1 \%$, from the vertebral artery in $1.9 \%$, as a single branch in $92.3 \%$, and as double branches in $7.7 \%$ (31). In the study by Martin et al. (24), the anterior inferior cerebellar arteries were seen to originate from the basilar arteries in all cadavers and as a single branch in $72 \%$, as two branches in $24 \%$, and as three branches in $2 \%$ of the cases (32).

When the relationship between the trigeminal nerves and vascular structures was examined, six vascular contacts to five (50\%) trigeminal nerves were seen, with four of these were superior cerebellar artery and two were anterior inferior cerebellar artery. In $10 \%$ of the cadavers, the contacts of both the superior cerebellar artery and the anterior inferior cerebellar artery to the nerve were observed. Venous compression was not observed in the 10 trigeminal nerves examined. There was no impression in the nerves due to the excessive propulsion or compression of the vessels. In the study by Rhoton on fresh cadaver, vessel-nerve contact was observed in $60 \%$ of the cases. In these cases, vascular contact was determined to be in the superior cerebellar artery in 52\% and inferior cerebellar artery in $8 \%$ of the cases. Displacements or grooves were not common in nerves (28). Ramesh found vascular contact to the trigeminal nerve in $39 \%$ of the cases in his study with fresh cadavers who did not have a history of pain on their faces. The cause of contact was the superior cerebellar artery in $23 \%$, anterior inferior cerebellar artery in $7 \%$, and venous vessels in $5 \%$ of the cases. Grooves or changes in the place of the trigeminal nerve were observed in $11 \%$ of the cases (33). In the study by Ćetković on fresh cadaver, vascular contact to the trigeminal nerve was observed in $56 \%$ of the cases. The cause of contact was the petrosal vein in $24 \%$, superior cerebellar arteries in $20 \%$, and anterior inferior cerebellar arteries in $12 \%$ of the cases. No distortion or groove formation in the nerve was observed (34). In the study by Janetta on 20 fresh cadavers and 20 patients with trigeminal neuralgia, 25\% arterial contact, 10\% arterial compression, $22.5 \%$ venous contact, and $10 \%$ venous compression in the trigeminal nerves in cadavers and 5\% arterial contact, $80 \%$ arterial compression, $22.5 \%$ venous contact, and $20 \%$ venous compression in patients with trigeminal neuralgia were observed (35). In the study by Canbolat on the nerve-vessel relationship of the trigeminal nerve in the cerebellopontine cistern on 50 fresh cadavers, nerve-vessel contact was seen in 40 trigeminal nerves. Bilateral nerve-vessel contact was observed in 10 cadavers. Nerve-vessel contact was observed to be in the superior cerebellar artery in 31 cases, in the anterior inferior cerebellar artery in five cases, and in the petrosal vein in seven cases (36).

Ueda evaluated 286 trigeminal nerves in a population that had no facial pain but had cranial MRI for any reason. Vascular contact of the nerves was observed in $28 \%$ of the cases in the study. The arterial structures causing the contact were observed to be only $79 \%$ of the superior cerebellar artery, $10 \%$ of the anterior inferior cerebellar artery, $4 \%$ of the superior cerebellar artery and the anterior cerebellar artery, and $>8 \%$ of the superior cerebellar arteries (37). In the study by Miller on 30 patients with trigeminal neuralgia and 15 patients without facial pain, arterial compression was determined to be $17 \%$ in asymptomatic patients, $57 \%$ on the same side in patients with trigeminal neuralgia, and $43 \%$ on the opposite side. Venous compression was $30 \%$ in asymptomatic patients, $90 \%$ on the same side in patients with trigeminal neuralgia, and $60 \%$ on the opposite side. The vascular structure responsible for arterial compression was found to be the superior cerebellar artery. Two anterior inferior cerebellar arteries in all nerves were observed to cause compression additionally. In patients with trigeminal neuralgia, in $83 \%$ of the cases, severe compression (displacement or grooving of the nerve) of the trigeminal nerve on the same side with symptoms was seen (38). In the study by Peker, a total of 200 trigeminal nerves were evaluated by 3 Tesla MR in 100 cases with no facial pain. Bilateral neurovascular compression was observed in $83 \%$ of the participants, and unilateral compression was observed in $9 \%$ of them. Neurovascular compression was found in $87.5 \%$ of a total of 200 trigeminal nerves. The vessels causing the neurovascular compression were observed to be $86 \%$ of the arteries and $14 \%$ of the veins (39).

In our study and in the studies of the authors conducted on cadavers without facial pain, it was seen that approximately $50 \%$ of the cadavers had vascular contact with the trigeminal nerve (33-39).

Barker published a series on microvascular decompression in 1185 patients with trigeminal neuralgia in 1996. In this series, compression was found to be $75 \%$ due to the superior cerebellar artery, $10 \%$ due to the inferior cerebellar artery, and $68 \%$ due to the venous vessels. When the early postoperative success rates of 1204 microvascular decompression operations were evaluated, complete recovery was reported as $82 \%$ and partial recovery as $16 \%$ after operation, complete recovery as $75 \%$ and partial recovery as $9 \%$ after 1 year, and complete recovery as $64 \%$ and partial recovery as $4 \%$ after 10 years. A total of 132 (11\%) patients were reoperated. In these operations, venous and/or small arterial structures were found as the cause of compression (40). In the study by Sindou et al. (33) on 579 patients, no vessel-nerve 
contact was observed in $3.3 \%$ of the patients. It was determined that vessels causing the contact were $88 \%$ of the superior cerebellar arteries, $25.1 \%$ of the anterior inferior cerebellar arteries, and $27.6 \%$ of the venous vessels. When the trigeminal nerves of patients with trigeminal neuralgia were examined, $17.6 \%$ simple contact, $49.2 \%$ distortion, and $33.2 \%$ grooving were observed. Complete remission was observed in $76.1 \%$ of the patients followed up for an average of 8 years. In the study by Pamir et al. (34) on the long-term follow-up of patients with trigeminal neuralgia in a series of 90 patients, it was reported that vascular compression on the trigeminal nerve was seen to be $97 \%$. The vessels causing the compression were determined to be the arteries in 92\% (80 patients) and the veins in 8\% (7 patients). The cause of the compression was arachnoid band and adhesions in $3 \%$ of the patients. When examining the vessels compressing the trigeminal nerve, it was seen that it was the superior cerebellar artery and its branch in 67 patients, anterior cerebellar artery in 10 patients, and venous vessels in three patients. Three patients did not benefit from microvascular decompression (74). In a series of 62 patients with typical trigeminal neuralgia on the long-term follow-up, Kabataş et al. (35) reported that the improvement of pain in the early postoperative period is excellent in $87.1 \%$ and good in $1.6 \%$. The second operation was performed in seven patients 24-96 h later due to the lack of improvement, and excellent results were obtained in all of these patients. On year 1 of follow-up, the results related to the pain of the patients were $83 \%$ excellent, $13.6 \%$ good, and $3.4 \%$ poor; on year 10 of controls, they were $63.8 \%$ excellent, $26.8 \%$ good, and $4.9 \%$ poor. It was seen that compression was caused only by arteries in $46.8 \%$ of the cases and only by veins in $17.7 \%$. The superior cerebellar artery was observed to be the vessel that was the most common cause of the compression (41).

The first case series on endoscope-assisted microvascular decompression in patients with trigeminal neuralgia was reported in 2000 by Shahinian et al. (13). In a series of 21 patients, 51 vessel compressions to the trigeminal nerves were observed. After microscopic decompression, $24 \%$ insufficient decompression was observed in the control with an endoscope. Fourteen (27\%) vessel compressions in the patients could be visualized only with an endoscope. In the series by Magnan et al. (16) related to endoscope-assisted microvascular decompression of 42 patients with trigeminal neuralgia, nerve-vessel relationship was shown in all patients. Superior cerebellar arteries in 64.3\%, superior cerebellar arteries and veins in 19\%, veins in $7.1 \%$, anterior inferior cerebellar arteries in 4.8\%, and superior cerebellar arteries and anterior inferior cerebellar arteries in $2.4 \%$ of the cases were determined as the cause of the compression in the trigeminal nerve. In the study by Teo et al. (18), all vessel-nerve relationships were visualized with the aid of an endoscope. The vessels compressing the veins were visualized inadequately in $33 \%$ of the 112 patients or could not be visualized at all in $8 \%$ with a microscope. The endoscope showed that $15 \%$ of the decompressions were said to be sufficient with microscope to be insufficient.

In a case series on endoscopic decompression in 255 patients with trigeminal neuralgia, Kabil et al. (4) showed the vessel-nerve relationship in all of the patients with an endoscope. The cause of the vascular compression was observed to be $58.8 \%$ superior cerebellar artery, $11.8 \%$ superior cerebellar artery and vein, $9.8 \%$ anterior inferior cerebellar artery, $9.8 \%$ vein, $5.6 \%$ superior cerebellar artery and anterior inferior cerebellar artery, and $3.9 \%$ anterior inferior cerebellar artery and vein. On month 3 of follow-up, 95\% of the patients recovered completely, $5 \%$ had adequate improvement, and $1 \%$ did not benefit. On year 3 of follow-up, 93\% had complete remission, $5 \%$ had adequate improvement, and $2 \%$ had no improvement (14).

\section{CONCLUSION}

The endoscopic approach has been found to be beneficial in surgical interventions for the cerebellopontine cistern. Although there are conventional approaches aimed at this area, endoscopic approaches will be more important in the future as they provide the chance of extensive imaging of this area. To perform endoscopic approaches more successfully, endoscopic anatomical studies and morphometric measurements related to the region are important to determine the reference points.

Ethics Committee Approval: Ethics committee approval was received for this study from the Ethics Committee of İstanbul University, İstanbul School of Medicine.

\section{Informed Consent: N/A}

Peer-review: Externally peer-reviewed.

Author Contributions: Concept - F.D., Ö.G., H.C., I.A.G., O.B.; Design F.D., Ö.G., H.C., I.A.G., O.B.; Supervision - F.D., Ö.G., H.C., I.A.G., O.B.; Resources - F.D., Ö.G., I.A.G.; Materials - F.D., Ö.G., I.A.G.; Data Collection and/or Processing - F.D., O.B.; Analysis and/or Interpretation - F.D., Ö.G., H.C., I.A.G., O.B.; Literature Search - F.D.; Writing Manuscript - F.D., O.B.; Critical Review - F.D., Ö.G., H.C., I.A.G., O.B.

Conflict of Interest: The authors have no conflict of interest to declare.

Financial Disclosure: The authors declared that this study has received no financial support.

\section{REFERENCES}

1. Rick Abbott History of neuroendoscopy. Neurosurg Clin N Am 2004; 15: 1-7. [CrossRef]

2. Doyen. Surgical therapeutics and operative technique. Bailliere, Tindall and Cox, editors London (1917). Vol. I: 599-60.

3. Prevedello DM, Doglietto F, Jane JA Jr, Jagannathan J, Han J, Laws ER Jr. History of endoscopic skull base surgery: its evolution and current reality. J Neurosurg 2007; 107: 206-13. [CrossRef]

4. Li KW, Nelson C, Suk I, Jallo GI. Neuroendoscopy: past, present, and future. Neurosurg Focus 2005; 19: 1-5. [CrossRef]

5. Jarrahy R, Eby JB, Cha ST, Shahinian HK. Full endoscopic vascular decompression of the trigeminal nerve. Minim Invas Neurosurg 2002; 45: 32-5. [CrossRef]

6. Gerard. M. O'Donoghue, Paul O'Flynn. Endoscopic anatomy of the cerebello-pontine angle. Am J Otol 1993; 14: 122-5.

7. Cappabianca P, Cavallo LM, Esposito F, de Divitiis E, Tschabitscher M. Endoscopic examination of the cerebellar pontine angle. Clin Neurol Neurosurg 2002; 104: 387-91. [CrossRef]

8. El-Garem HF, Badr-El-Dine M, Talaat AM, Magnan J. Endoscopy as a tool in minimally invasivetrigeminal neuralgia surgery. Otology Neurotol 2002; 23: 132-5. [CrossRef]

9. Kabil MS, Eby JB, Shahinian HK. Endoscopic vascular decompression versus micro-vascular decompression of the trigeminal nerve. Minim Invas Neurosurg 2005; 48: 207-12. [CrossRef]

10. Artz GJ, Hux FJ, Larouere MJ, Bojrab DI, Babu S, Pieper DR. Endoscopic vascular decompression. Otol Neurotol 2008; 29: 995-1000. [CrossRef] 
11. Yin X, Xi-ping L, De-min H, Jun Z, Hai-shan L, Jin-feng S. Anatomic structural study of cerebellopontine angle via endoscope. Chin Med J 2007; 120: 1836-9. [CrossRef]

12. Chaynes P, Deguine $O$, Moscovici J, Fraysse B, Becue J, Lazorthes $Y$. Endoscopic anatomy of the cerebellopontine angle: a study in cadaver brains. Neurosurg Focus 1998; 5: e8. [CrossRef]

13. Jarrahy R, Berci G, Shahinian HK. Endoscope-assisted microvascular decompression of the trigeminal nerve. Otolaryngol Head Neck Surg 2000; 123:218-23. [CrossRef]

14. Uz A, Ugur HC, Tekdemir I. Is the asterion a reliable landmarkfor lateral approach to posterior fossae? J Clin Neuro 2001; 8: 146-7. [CrossRef]

15. Srijit D, Rajesh $\mathrm{S}$, Vijay K. Topographical anatomy of asterion by an innovative technique using transillumination and skiagram. Chin Med J 2007; 120: 1724-6. [CrossRef]

16. Tanriover N, Abe H, Rhoton AL Jr, Kawashima M, Sanus GZ, Akar Z. Microsurgical anatomy of the superior petrosal venous complex: new classifications and implications for subtemporal transtentorial and retrosigmoid suprameatal approaches. J Neurosurg 2007; 106 : 1041-50. [CrossRef]

17. Rak R, Sekhar LN, Stimac D, Hechl P. Endoscope-assisted microsurgery for microvascular compression syndromes. Neurosurgery 2004; 54: 876-83. [CrossRef]

18. Teo C, Nakaji P, Mobbs RJ. Endoscope-assisted microvascular decompression for trigeminal neuralgia: technical case report. Neurosurgery 2006; 59: 489-90.

19. Jarrahy R, Eby JB, Shahinian HK. A new powered endoscope holding arm for endoscopic surgery for the cranial base. Minim Invas Neurosurg 2002; 45: 189-92. [CrossRef]

20. Morita A, Shin M, Sekhar LN, Kirino T. Endoscopic microneurosurgery: usefulness and cost-effectiveness in the consecutive experience of 210 patients. Neurosurgery 2006; 58: 315-21. [CrossRef]

21. Mwachaka PM, Hassanali J, Odula PO. Anatomic Position of the Asterion in Kenyans for Posterolateral Surgical Approaches to Cranial Cavity. Clinical Anatomy 2010; 23: 30-3.

22. Ucerler H, Govsa F. Asterion as a surgical landmark for lateral cranial base approaches. J Craniomaxillofacial Surg 2006; 34: 415-20. [CrossRef]

23. Aysun $\mathrm{U}, \mathrm{U}$ gur $\mathrm{H}$, Tekdemir I. Is the asterion a reliable landmark for lateral approach to posterior fossae? J Clin Neuro 2001; 8: 146-7. [CrossRef]

24. Srijit D, Rajesh S, Vijay K. Topographical anatomy of asterion by an innovative technique using transillumination and skiagram. Chin Med J (Engl) 2007; 120: 1724-6. [CrossRef]

25. Tanriover N, Abe H, Rhoton AL Jr, Kawashima M, Sanus GZ, Akar Z. Microsurgical anatomy of the superior petrosal venou complex: new classifications and implications for subtemporal transtentorial and retrosigmoi suprameatal approaches. J Neurosurg 2007; 106: 1041-50. [CrossRef]

26. Rhoton AL. The Posterior Fossa Cisterns. Neurosurgery 2000; 47: 287-97. [CrossRef]
27. Yasargil MG, Kasdaglis K, Jain KK, Weber HP. Anatomical observations of the subarachnoid cisterns of the brain during surgery. $\mathrm{J}$ Neurosurg 1976; 44: 298-302. [CrossRef]

28. Hardy DG, Rhoton AL. Microsurgical relationships of the superior cerebellarartery and trigeminal nerve. J Neurosurg 1978; 49: 669-78. [CrossRef]

29. Han J. Microanatomical relationships of the anterior inferior cerebellar artery and the facial nerve. Zhonghua Er Bi Yan Hou Ke Za Zhi 1990; 25: 133-4.

30. Yurtseven T, Savaş R, Koçak A, Turhan T, Aktaş EO, Işlekel S. Relationship between anterior inferior cerebellar artery and facial-vestibulocochlear nerve complex: an anatomical and magnetic resonance images correlation study. Minim Invasive Neurosurg 2004; 47: $306-$ 11. [CrossRef]

31. Kim HN, Kim YH, Park IY, Kim GR, Chung IH. Variability of the surgical anatomy of the neurovascular complex of the cerebellopontine angle. Ann Otol Rhinol Laryngol 1990; 99: 288-96. [CrossRef]

32. Martin RG, Grant JL, Peace D, Theiss C, Rhoton AL Jr. Microsurgical relationships of the anterior inferior cerebellar artery and the facial-vestibulocochlear nerve complex. Neurosurgery 1980; 6: 483-507. [CrossRef]

33. Ramesh VG, Premkumar G. An anatomical study of the neurovascular relationships at the trigeminal root entry zone. J Clin Neurosci 2009; 16: 934-6. [CrossRef]

34. Cetković M, Antunović V, Marinković S, Todorović V, Vitošević Z, Milisavljević M.Vasculature and neurovascular relationships of the trigeminal nerve root. Acta Neurochir 2011; 153: 1051-7. [CrossRef]

35. Haines SJ, Jannetta PJ, Zorub DS. Microvascular relations of the trigeminal nerve. J. Neurosurg 1980; 52: 381-6. [CrossRef]

36. Ali Tuncay Canbolat (1981). Nervus trigeminus kökünün pons seviyesinde nörovasküler komşulukları. Uzmanlık tezi.

37. Ueda F, Suzuki M, Fujinaga Y, Kadoya M, Takashima T. In vivo anatomical analysis of arterial contact with trigeminal nerve: detection with three-dimensional spoiled grass imaging. Br J Radiol 1999; 72 : 838-45. [CrossRef]

38. Miller JP, Acar F, Hamilton BE, Burchiel KJ. Radiographic evaluation of trigeminal neurovascular compression in patients with and without trigeminal neuralgia. J Neurosurg 2009; 110: 627-32. [CrossRef]

39. Peker S, Dinçer A, Necmettin Pamir M. Vascular compression of the trigeminal nerve is a frequent finding in asymptomatic individuals 3-T MR imaging of 200 trigeminal nerves using 3D CISS sequences. Acta Neurochir 2009; 151: 1081-8. [CrossRef]

40. Barker FG, Jannetta PJ, Bissonette DJ, Larkins MV, Jho HD. The long-term outcome of microvascular decompression for trigeminal neuralgia. N Engl J Med 1996; 334: 1077-83. [CrossRef]

41. Kabatas S, Karasu A, Civelek E, Sabanci AP, Hepgul KT, Teng YD. Microvascular decompression as a surgical managementfor trigeminal neuralgia: long-term follow-up and reviewof the literature. Neurosurg Rev 2009; 32: 87-94. [CrossRef] 